\title{
ENABLING HIGH-ACCURACY, POSITION MONITORING OF SABLE ISLAND THROUGH THE NOVA SCOTIA COORDINATE REFERENCING SYSTEM
}

\author{
JASON BOND* \\ Department of Internal Services, \\ Province of Nova Scotia, Halifax, Nova Scotia, Canada
}

\begin{abstract}
Since 1968, the Province of Nova Scotia has carried out a mandate of providing coordinate referencing infrastructure for its citizens. The current infrastructure is known as the Nova Scotia Coordinate Referencing System (NSCRS) and allows property boundaries, engineering works, and natural features to be spatially related within the Province, including Sable Island. Traditionally, thousands of survey monuments across the Province provided access to the coordinate referencing system for surveying and engineering work. Of the original 23,000 monuments installed in the 1970s and 1980s, many have been destroyed by natural occurrences or human activities. In the case of Sable Island, most have been enveloped by sand or the sea. In 2013, the Province began implementing a modernized strategy for delivering coordinate referencing services to its citizens using permanent GPS stations. This technology was installed at Main Station on Sable Island in June of 2014. This GPS infrastructure has already had a positive impact by:

a) Allowing, for the first time, the three dimensional position of Sable Island (specifically Main Station) to be monitored with millimeter level accuracy

b) Enabling Light Detection and Ranging (LiDAR) and aerial photography surveys to be consistently referenced within a global reference frame; and

c) Providing quick and accurate positioning of natural features around the island with millimeter level accuracy and consequently enabling long term, position trends of these features (e.g., Bald Dune) to be determined.
\end{abstract}

Each of these topics is discussed and a history of the NSCRS on Sable Island is presented.

Keywords: coordinate referencing, Sable Island, GPS, positioning 


\section{INTRODUCTION}

Since 1968, the Province of Nova Scotia has carried out a mandate of providing coordinate referencing infrastructure for its citizens. The current infrastructure is known as the Nova Scotia Coordinate Referencing System (NSCRS) and allows property boundaries, engineering works, and natural features to be spatially related within the Province, including Sable Island. In the 1970s, thousands of survey monuments were installed across the Province to realize the coordinate referencing system. This initiative was extended to Sable Island in the early 1980s.

Historically, the requirement for an accurate coordinate referencing system has been largely driven by the need for administering property rights. As areas develop and civil infrastructure becomes more commonplace, demands for land and its resources necessitate accurate land information and land information management systems. Increasing environmental concerns and needs for natural resources continue to escalate the need for the management of interests in land and its resources.

The need for reliable positions for navigation hazards around Sable Island has existed for hundreds of years. Although advances in technology have nearly eliminated shipwrecks around Sable Island, the need for accurate position continues to exist. For example, efforts to extract natural gas near Sable Island have made it necessary to accurately demarcate offshore reserves. Additionally, there are ongoing requirements to accurately map vegetation, topography, and changes in freshwater resources, as well as to determine the long term movement of the Island itself.

Of the original 23,000 survey monuments installed in the 1970 s and 1980s, many have been destroyed by natural occurrences or human activities. In the case of Sable Island, most survey monuments have been enveloped by sand or the sea. In 2013, the Province began implementing a modernized strategy for delivering coordinate referencing services to its citizens using permanent Global Positioning System (GPS) stations. This technology was installed at Main Station on Sable Island in June of 2014. The GPS infrastructure has already had a positive impact by: 
a) Allowing, for the first time, changes in the three dimensional position of Sable Island (specifically Main Station) to be monitored with millimeter level accuracy;

b) Enabling Light Detection and Ranging (LiDAR) and aerial photography surveys to be consistently referenced within a global reference frame; and

c) Providing quick and accurate positioning of natural features around the island with up to millimeter level accuracy and consequently enabling long term, position trends of these features (e.g., Bald Dune) to be determined.

Presented is a discussion on how coordinate referencing has evolved to its current state on Sable Island. An overview of the GPS technology that was recently installed to enable high precision positioning is also provided. Positioning results from the initial year of GPS data are presented, which illustrate how the 3D position of Sable Island is changing. Applications of the GPS technology to positioning aircraft with onboard sensors and to monitoring the Island's physical landscape are also described.

\section{COORDINATE REFERENCING ON SABLE ISLAND}

Like most jurisdictions in Canada, the federal government provided the foundation for the coordinate referencing system on Sable Island. The Canadian Hydrographic Service's (CHS) nautical charting mandate drove the need to establish reliable positions for navigation aids and hazards on and around Sable Island. The lighthouse located on the eastern end of the island ("East Lighthouse") was one of the first coordinated survey monuments on Sable Island. Its position was derived using astronomic positioning methods (Gray 1971) after it was constructed in 1873 (Stephens 1973).

The introduction of precise Electronic Distance Measurement (EDM) technology in the mid-1950s lead to more efficient and more accurate methods for conducting survey work. In 1963, CHS endeavored to utilize EDM technology to establish a network of survey monuments with known position across Sable Island (Gray 1971). R Wills was the CHS Officer-in-Charge at that time. A Tellurometer EDM (see Fig 1) was used to perform three, adjacent, survey traverses. The basic operation principle of the Tellurometer was that it determined distance 
by measuring the roundtrip travel time of reflected microwaves. In total, twenty-one survey stations were used in the traverses, seven of which were made permanent to establish a coordinate referencing framework (CHS 1963).

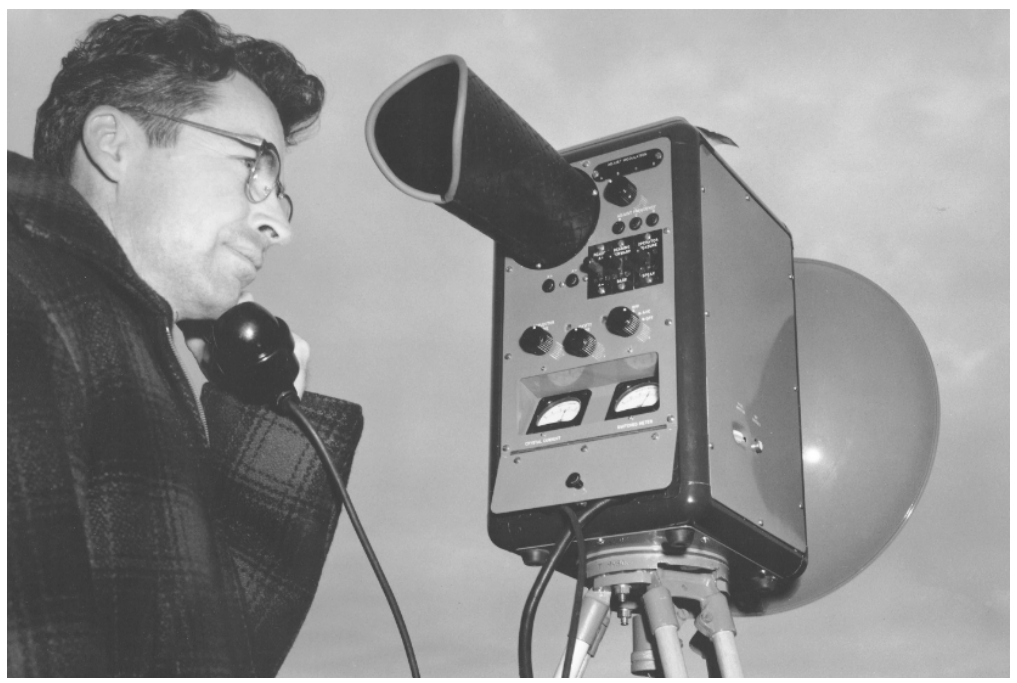

Fig 1 Tellurometer EDM (USGS, 20130.

EDM technology also allowed the absolute accuracy of the survey network to be improved. Aerodist was used to position station RED Electric Center (E/C) (Gray 1971). Aerodist is an adaption of Tellurometer technology to an airborne platform which overcomes line-of-sight limitations of ground based measurements.

With Aerodist measurements, a master transmitter is setup in an aircraft and two ground stations are established. To determine the distance between them, the aircraft flies approximately midway between the two stations while transmitting to the ground stations. The recorded distances become shorter as the aircraft approaches collinearity with the two ground stations. The height of the aircraft is also recorded. The horizontal distance is estimated by assuming two right angled triangles are formed and using the shortest measured slope distance, estimated at time, $t 1$, in Fig 2 . The process is repeated multiple times to improve accuracy (Tuttle 1967). 


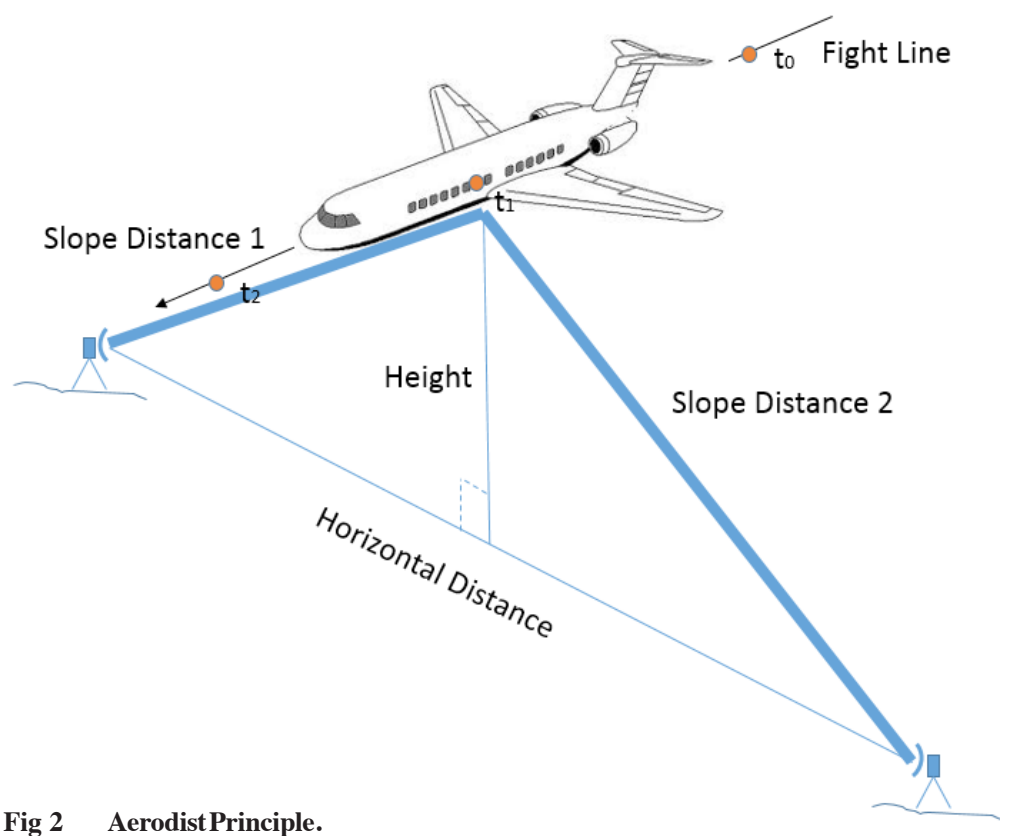

Fig 2 Aerodist Principle.

The absolute accuracy of RED E/C was estimated to be at meter level using the Aerodist results. Orientation was obtained for the survey traverses by using astronomic observations between station RED $\mathrm{E} / \mathrm{C}$ and station POD. The positions of the seven survey monuments placed relative to RED E/C were estimated to meet second order or better survey tolerances as published in the 1961 specifications from the Department of Energy, Mines and Resources (Gray 1971).

In the late 1960s, Doppler technology emerged for geodetic positioning applications (for a discussion on Doppler positioning, see Wells (1974) and Aerospace (2010)). The US Navy's Doppler based Transit system was declared operational in 1964. Transit was based on a Doppler ranging principle. Because of the many similarities Transit has with GPS, it can be considered the forefather of GPS (Aerospace 2010). Transit avoided the high cost associated with using an aircraft for Aerodist measurement techniques. Station REDE/C was positioned using Doppler technology by A.R. Eaton of Geodetic Survey Division in 1976 (Lapelle 2015).

During the late 1970s and early 1980s, the three Maritime Provinces underwent a massive effort to implement a coordinate referencing framework through the Land Registration and Information Service 
(LRIS). The reference framework put in place was state-of-the-art. Over 23,000 survey monuments (see Fig 3) were installed in Nova Scotia. The coordinate referencing system was named the Nova Scotia Coordinate Control System (NSCCS) and it is the predecessor to the NSCRS.Practically every inhabited road in Nova Scotia had a survey monument installed with $1 \mathrm{~km}$ spacing or less (see Fig 4). Sable Island was also included in this initiative, as illustrated in Fig 4 and Fig 5.

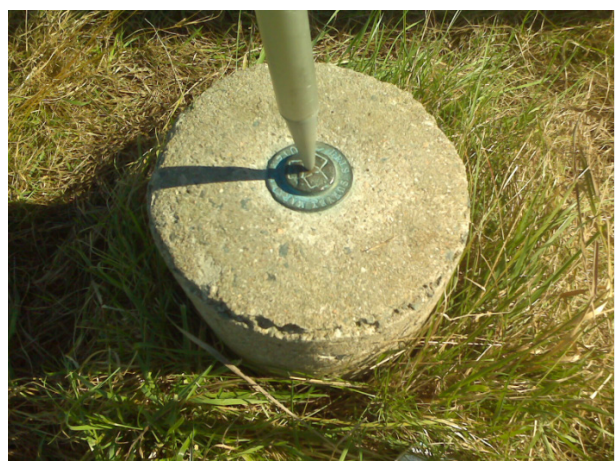

Fig 3 Nova Scotia Survey Monument.

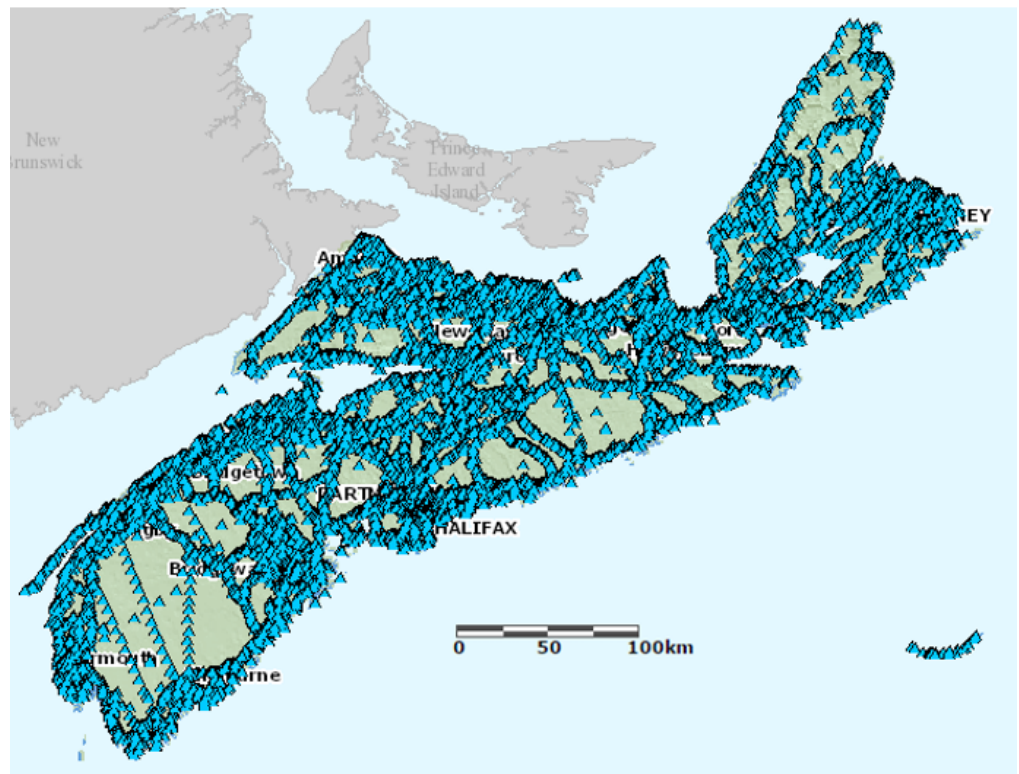

Fig 4 NSCCS Reference Framework. 


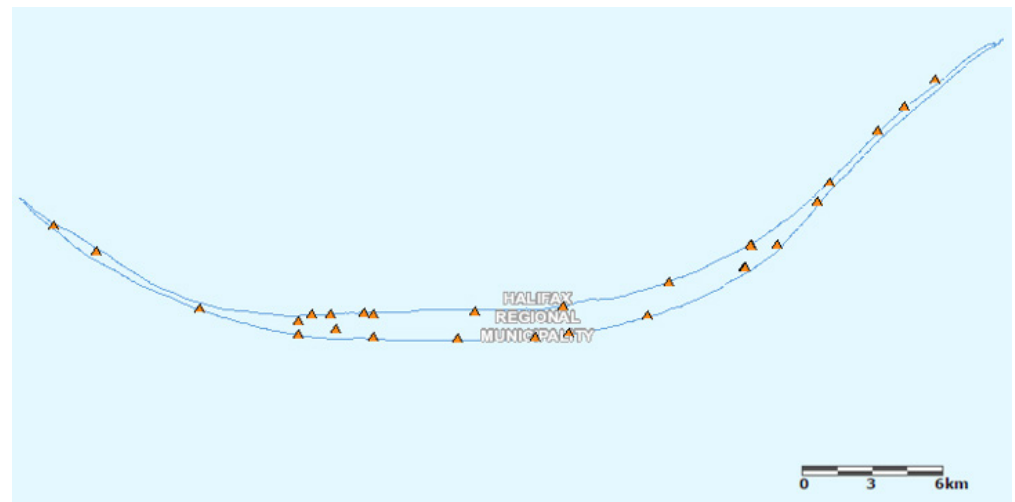

Fig 5 Location of Nova Scotia Survey Monuments placed on Sable Island in the early 1980s.

Several parties contributed to the survey work required to realize the coordinate referencing framework on Sable Island including:

i) McElhanney Ltd: performed reconnaissance and observation work (Swan 1985)

ii) LRIS: placed and surveyed approximately 20 survey monuments (inch square iron bars with caps). The surveys were based off of the Federal primary network monuments (SABLE, RED, EAST LIGHT, WEST LIGHT) (Robertson 2015)

iii) Geodetic Survey Division: performed observations (including astronomic observations) (Lapelle 2015).

Fig 6 and Fig 7 illustrate site sketches for two of the survey monuments placed on Sable Island during this period. The absence of notable landmarks in the sketches other than sand dunes illustrates how difficult it would be to reestablish the location of a monument over time. Coordinates were calculated and published by LRIS in the Average Terrestrial System of 1977 (ATS77) datum.

In the late 1980s, GPS began replacing the Doppler based Transit system for geodetic positioning because of its higher accuracy. In 1991, Nortech Atlantic Ltd. and McElhanney were contracted to perform survey network densification on Sable Island using GPS. RJ Morris from Geodetic Survey Division was involved as Senior Geodetic Surveyor. LRIS also assisted in the densification effort. Nortech was also contracted to establish positions of the offshore platforms Panuke 


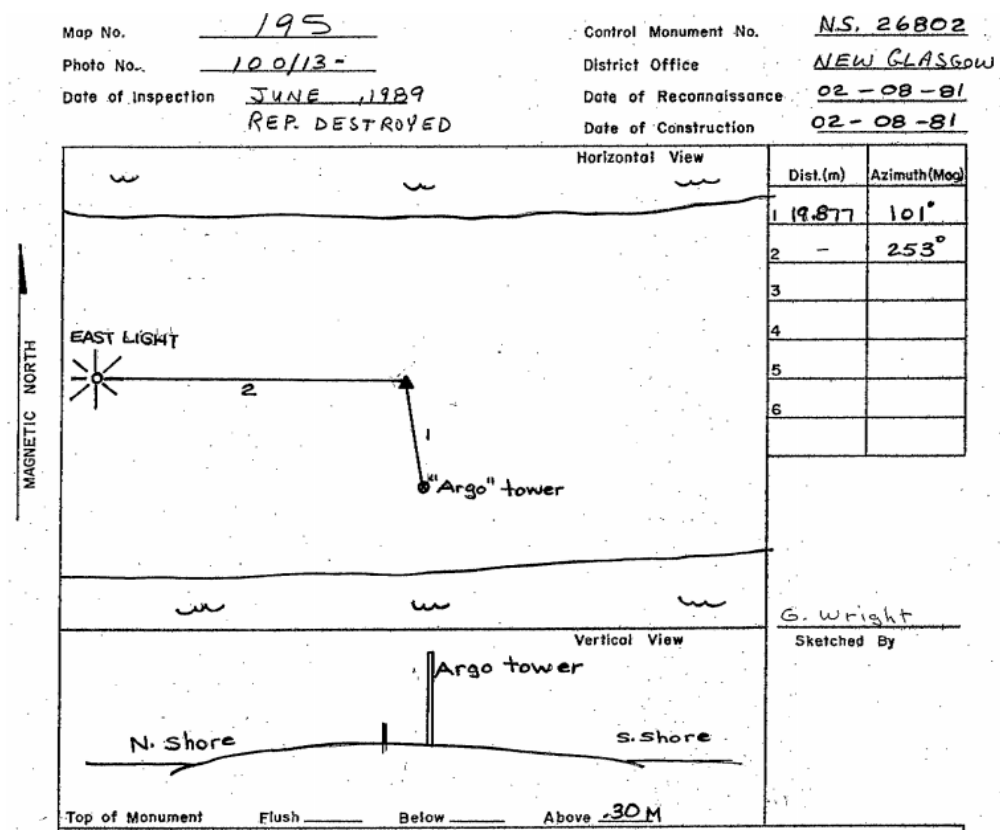

Fig 6 Survey Monument Sketch for Station \# 26802.

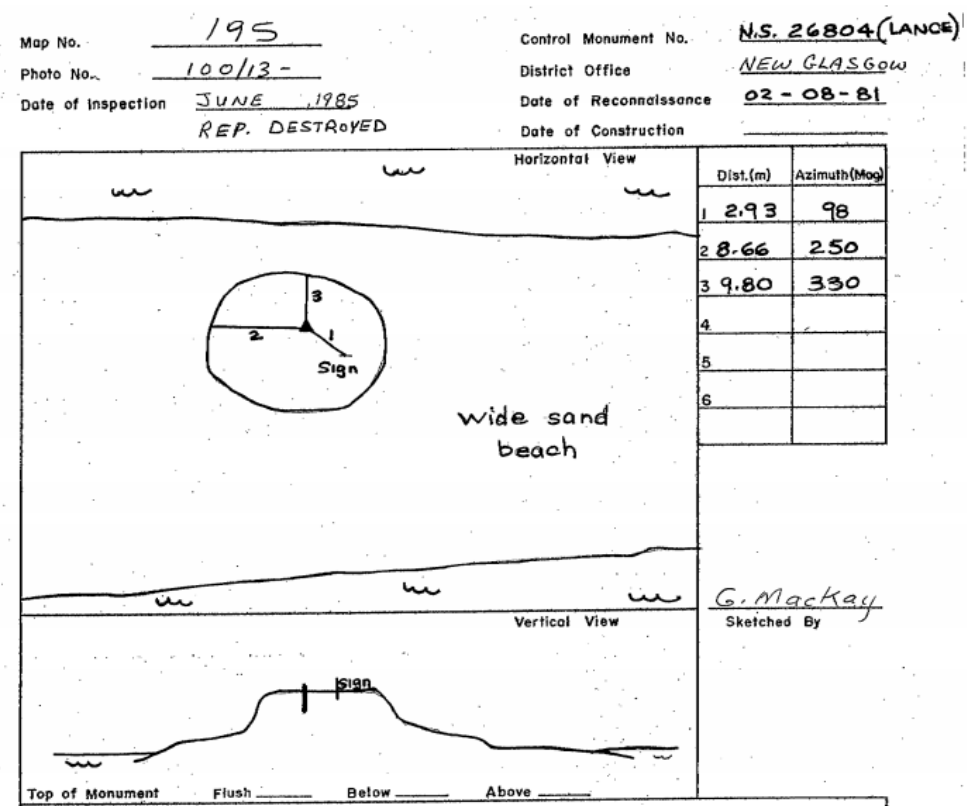

Fig 7 Survey Monument Sketch for Station \# 26804 (LANCE). 
and Cohasset which were located near Sable Island. This work was required to meet national standards for the survey of Canada Lands (Morris 2015, Pyke 2015).

Through this collaborative effort, RED E/C and SHEROD were positioned relative to three, Federal, Primary Network stations on the mainland of Nova Scotia (CROWDIS, SHAFFELBURG, MILLS). Dual frequency GPS receivers were used to make 5 sets of 4 hour GPS sessions. The positions of RED E/C and SHEROD were estimated by Geodetic Survey Division (now Canadian Geodetic Survey) to have \pm 2 centimeter accuracy horizontally and \pm 4 centimeter accuracy vertically. NS28960, NS28961, NS28962 (WESTLIGHT), NS28966 (WALLACE), NS28963 and NS28967 (LOCKOS) were also observed with GPS during this campaign to densify the survey network. These secondary network points were occupied using a single, 2-hour session (Lapelle 2015). In the fall of 1992, follow up survey work (GPS, EDM) was performed by Nortech to measure newly placed survey monuments (Sherod 2015).

It is noteworthy that the survey work performed in the fall of 1991 occurred during the fury of the "Perfect Storm" (Morris 2015, Pyke 2015, Pottier 2015). For insurance purposes, surveyors from Nortech were obligated to "watch" the unmanned platforms in " 50 ' high seas" (Pyke 2015). On the island, the survey crew took refuge in a Quonset hut as the Atlantic Ocean ravaged across the Island.

Between 1993 and 2014, coordinate referencing maintenance work on Sable Island was limited. As was the case on the Nova Scotia mainland, without ongoing maintenance the survey monument infrastructure began to deteriorate. Even as early as 1989, McElhanney had reported that most of the survey monuments put in place a few years prior had been destroyed. This is indicated on the LRIS survey monument sketches. The aggressive forces of nature on Sable Island made it particularly challenging to maintain the infrastructure. Most of the survey monuments were enveloped by sand or the sea over time.

In 2014, Nova Scotia's Topographic Database Program was scheduled to capture aerial photography over Sable Island. With aerial photo image resolution approaching $20 \mathrm{~cm}$, it was required to provide accurately positioned ground targets to geo-reference and quality control the imagery. Additionally, to position the aircraft during post processing, an accurately positioned GPS base station was required. On the mainland, a modernization effort was underway to address coordinate referencing needs by using permanently installed GPS stations that 
could provide up to millimeter level positioning accuracy. The timing was right to extend the strategy to Sable Island. Table 1 summarizes the aforementioned technologies used to determine absolute position on Sable Island and their achievable accuracies.

Table 1 Summary of Technologies Used for Positioning on Sable Island

\begin{tabular}{lcl}
\hline Technology & Implementation in Canada & Achievable Accuracy \\
\hline $\begin{array}{l}\text { Astronomical Observations } \\
\text { with Theodolite }\end{array}$ & Late $1800 \mathrm{~s}$ & Few metres \\
AeroDist (EDM based) & $1960 \mathrm{~s}$ & metre \\
Doppler & $1960 \mathrm{~s}$ & decimetres \\
Campaign Based GPS & $1980 \mathrm{~s}$ & centimetres \\
Permanent GPS & $1990 \mathrm{~s}$ & millimetres \\
\hline
\end{tabular}

\section{COORDINATE REFERENCING SYSTEM MODERNIZATION}

Just like any other infrastructure, maintenance is required to keep a coordinate referencing system functional. Infrastructure maintenance includes clearing out obstructions (e.g., vegetation) surrounding monuments and opening lines-of-sight between them. It also involves periodically updating coordinates with new observations and replacing or repairing destroyed or damaged monuments. The large number of monuments installed during the 1970s as part of the NSCCS made ongoing maintenance a constant struggle because of the significant expense associated with it. By the end of the 1980s, it was apparent that the lack of available funding to maintain the NSCCS was taking its toll. In 1989, a $\$ 2.25$ million proposal was put forward to do a single cycle of maintenance on the reference frame. This involved inspecting and densifying the existing network over a 5 year period. The proposal was rejected due to the high cost (NSLUC 1995).

The state of the NSCCS survey monument infrastructure would undergo a steady decline over the next two decades. In recent years, it has been estimated that 25\% (more than 5000) of the NSCRS survey monuments have been destroyed and that over $50 \%(12,500)$ of the infrastructure is unusable due to forest overgrowth. Additionally, with the emergence of high accuracy GPS, Nova Scotia Land Surveyors (NSLS) noticed that the accuracy of the NSCCS, which uses the ATS77 datum and was realized using EDM and theodolite instruments, was not sufficient to support GPS technology. Two main 
requirements emerged from industry: a) improved accessibility to the survey monument infrastructure and b) improved accuracy to support GPS technology.

In the late 1990s, the Province attempted to address the need to provide a GPS compatible referencing system through the implementation of the NSCRS. The NSCRS was realized through the Nova Scotia High Precision Network (NSHPN) which consisted of 153 survey monuments that were observed with GPS. At that time, the spacing of the NSCMs which comprised the NSHPN was approximately 20 $\mathrm{km}$. Because the framework did not address the need for improved accessibility, it was not widely used.

Fortunately, new technologies emerged that presented significant opportunities for the NSCRS program to deliver on its mandate with fewer resources than were required in the past. These were:

a) Active Control Stations (ACS): GPS hardware permanently installed on selected survey monuments allowed users to receive differential corrections and achieve centimeter level positioning in real-time.

b) Network Real-time Kinematic (NRTK) GPS: Networks of ACSs allowed differential corrections to be more accurately modelled. This cut the distance from reference station error from $1 \mathrm{~mm} /$ $\mathrm{km}$ to $0.5 \mathrm{~mm} / \mathrm{km}$ within the station network.

c) Cellular communications: Cellular coverage made it possible to receive NRTK GPS corrections throughout most of the Province.

In 2013, the NSCRS program began testing the suitability of an active network of GPS stations, the Nova Scotia Active Control Stations (NSACS) network, as a means of delivering its coordinate referencing mandate. Eight active stations were installed in southwest Nova Scotia. The results were positive and highlighted several key benefits including:

i) Requiring fewer stations. Approximately 40 stations would be required to cover all of Nova Scotia to deliver a higher level of service than with the passive approach.

ii) Higher accuracy and greater accessibility.

iii) Promoting a more sustainable maintenance model because of the lighter infrastructure. 
iv) Allowing for more efficient updates and maintenance of traditional passive monuments.

v) Creating efficiencies for surveyors

vi) Creating efficiencies in other industries through machine automation (agriculture, construction, navigation)

In 2014, the Nova Scotia Coordinate Referencing Program approached Parks Canada about the possibility of locating an ACS on Sable Island.In addition to providing a mechanism for geo-referencing the aerial photography about to be flown, the installation of a permanent, active, GPS station on Sable Island would also offer the following benefits:

a) Long term tracking of the position of Sable Island: Plate tectonics causes constant changes in the earth's surface. These changes can be modelled over time by sampling the position of points over the earth with GPS. Generally, the higher the sampling resolution, the more accurate the model. Since 1994, Natural Resources Canada has been collecting data to model the movements of the North American Plate (Henton et al.2006). The addition of a permanent, active, GPS station on Sable Island would provide a new sample point detached from the mainland of Nova Scotia. This would allow the long term movements of this GPS reference station to be tracked and in turn provide information on how Sable Island is moving both horizontally and vertically. Movements of a similar station at the Bedford Institute of Oceanography in Dartmouth, have revealed that Nova Scotia is subsiding at approximately 2 $\mathrm{mm} /$ year (Craymer et al. 2012).

b) Feature management: The use of real-time, kinematic (RTK) GPS is common for mapping applications. This technology would allow vegetation to be mapped with centimetre level accuracy. The same vegetation could be mapped at a later date to see if it is increasing or decreasing in coverage. Similarly, sand dunes or coast lines could be quickly mapped with high accuracy at various intervals to monitor movement over time. If communications infrastructure is available, positions could be calculated in realtime in the field. Otherwise, data could be collected in the field and post-processed with the data collected at the ACS to calculate precise positions. 
c) Asset management: Buildings and structures on Sable Island could be mapped with high accuracy using the technology. The information would help in planning for future developments.

d) Precise, inshore navigation: Corrections from the Active Control Station could be broadcast and received by vessels approaching Sable Island to allow for precise navigation. In order for this technology to work, the ACS must be connected to a communications system.

e) Precise, offshore positioning: Data from the ACS could be used for precise, offshore positioning of vessels such as oil platforms and for submarine cables and pipes.

f) LiDAR and Aerial Photography Aircraft Positioning: Data from the ACS could be used for calculating positions of the aircraft collecting data for LiDAR or aerial photography applications. Having the same reference stations allows for better homogeneity in results.

g) Geo-referencing of LIDAR and Aerial Photography: The ACS infrastructure allows aerial targets to be easily deployed and surveyed within the same coordinate system as the ACS. This facilitates geo-referencing and quality control work of LiDAR and aerial photography data.

In June of 2014, through a collaborative effort between the Province of Nova Scotia and Parks Canada, the NSACS was extended to Sable Island. The GPS antenna was mounted on the garage at Main Station (Fig 8). The garage is made of cinder block, which minimizes thermal impacts on the position solutions for the station. The garage has a concrete foundation and represents one of the more stable structures on the island. The GPS receiver is connected to a local WiFi network, allowing its data to be retrieved by users for post processing every 24 hours.

RTK solutions with centimeter level accuracy can be obtained if the user is within range of the WiFi network. At the time of installation, the range of the WiFi network was, at best, $1.5 \mathrm{~km}$. Alternatively, position can be determined anywhere on the island relative to the ACS by collecting data over the point of interest and differentially post-processing the data with GPS software. This is known as a static survey.

A third scenario exists which utilizes a combination of the first and second techniques. In this approach, the user employs a traditional 


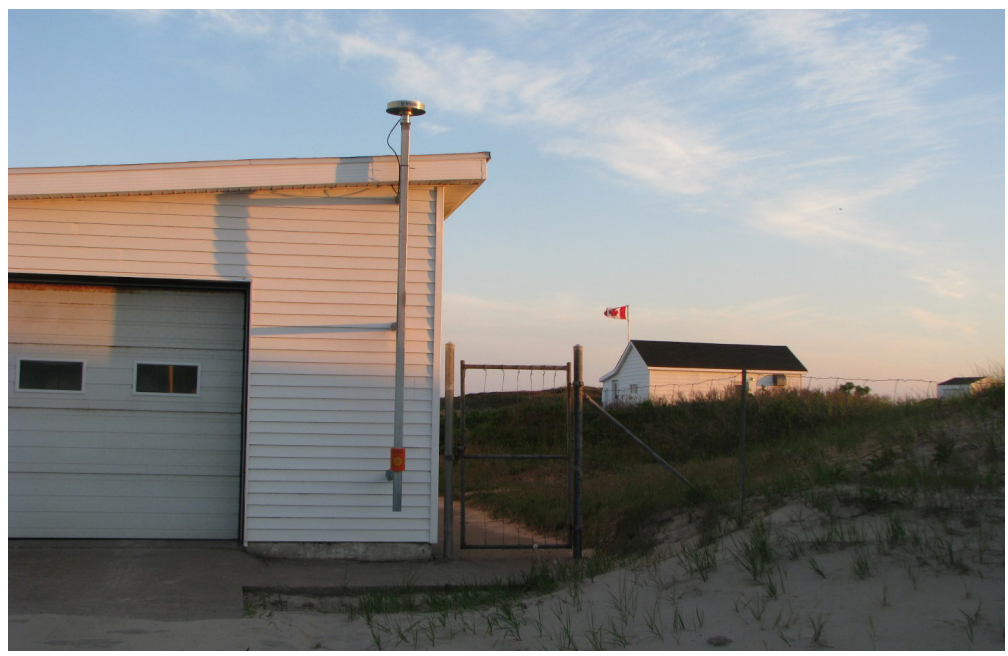

Fig 8 Nova Scotia Active Control Station located on the Garage at Main Station, Sable Island.

reference station and rover station setup. The reference station can be deployed in a convenient location near the work site to perform the RTK survey. The reference station should be conFigd to log data so that its position can be precisely calculated relative to the nearest ACS. If accurate, real-time coordinates are required (e.g., for a stakeout survey), then the position of the base will need to be calculated relative to SABL using static post processing prior to conducting the RTK survey.

If accurate coordinates are not immediately required (e.g., for a topographic survey), then kinematic data collection can occur without a radio and the entire survey can be post processed using appropriate software in post-processed kinematic (PPK) mode. A variant on this technique is to conduct a RTK survey using a radio and approximate coordinates at the local reference station. The survey can be later shifted by assigning accurate coordinates for the reference station once they are calculated. The advantage of using a radio is that there is less chance of not being aware of unresolved ambiguities on points observed in kinematic mode which would only otherwise show up in post processing.

The local reference station helps to ensure that distances to the roving station are kept short so that ambiguities can be resolved. If the work site is within a few kilometers of SABL and a radio is not 
in use, it may not be advantageous to establish a local reference station since the kinematic data can be post processed relative to SABL directly. Fig 9 illustrates the different survey scenarios that exist on Sable Island using the ACS.
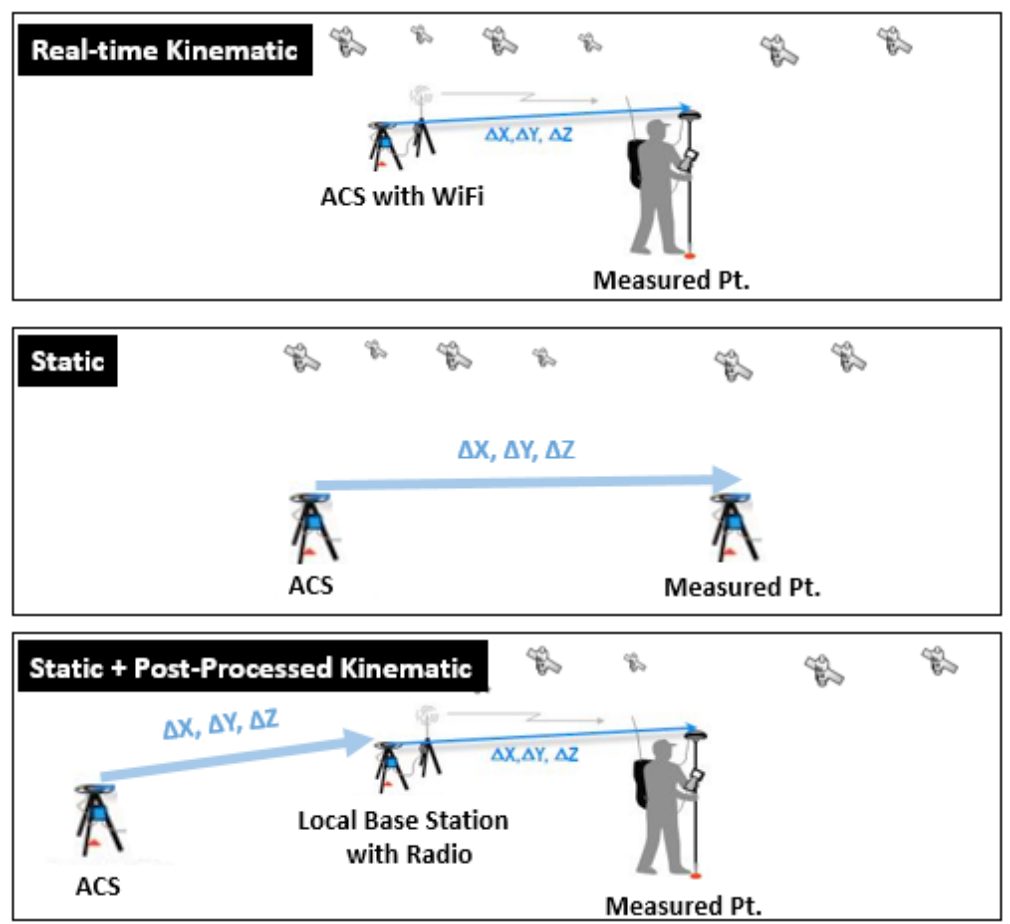

Fig 9 Surveying Scenarios using the Active Control Station on Sable Island.

The coordinates for the ACS on Sable Island ("SABL") have been estimated by Natural Resources Canada with millimeter level accuracy. Using RTK positioning, real-time positions for the rover relative to the ACS can be calculated with a precision of approximately $\pm 20 \mathrm{~mm}+1 \mathrm{ppm}$ horizontally and $\pm 30 \mathrm{~mm}+1 \mathrm{ppm}$ vertically. For example, at a distance of $10 \mathrm{~km}$ from SABL ACS, one could expect real-time position accuracies of about $\pm 30 \mathrm{~mm}(20 \mathrm{~mm}+10 \mathrm{~mm})$ horizontally and $\pm 40 \mathrm{~mm}(30 \mathrm{~mm}+10 \mathrm{~mm})$ vertically. The above values assume that the rover has good visibility to satellites distributed evenly across the sky. In poor GPS conditions, the expected accuracies would deteriorate. To obtain higher accuracy, static positioning 
is required. Longer observations sessions allow error sources to be reduced to millimeter level. The length of time required to achieve high accuracy is dependent upon a number of factors including the distance from the ACS, satellite visibility and type of GPS hardware. On the mainland of Nova Scotia, the distance dependent accuracy specification can be reduced from $1 \mathrm{ppm}$ to $0.5 \mathrm{ppm}$ since a network of ACSs can be used to model real-time corrections.

\section{REALIZATION OF ACS BENEFITS}

Shortly after installation, the data from SABL ACS was used by the Nova Scotia Topographic Database program to calculate the position of an aircraft capturing high resolution, aerial photography of Sable Island. It was also used to determine the position of aerial targets (Fig 10) and to quality control the data. The imagery collected using the ACS infrastructure allows qualitative changes of Sable Island to be monitored over time. Fig 11 illustrates aerial photography of Sable Island collected in May of 1972 and in September of 2014. As image resolution becomes higher, the needs for better geo-referencing capabilities also increase. The ACS infrastructure can meet this need. Fig 12 illustrates the 2014 digital imagery with spatial resolution of up to $20 \mathrm{~cm}$.

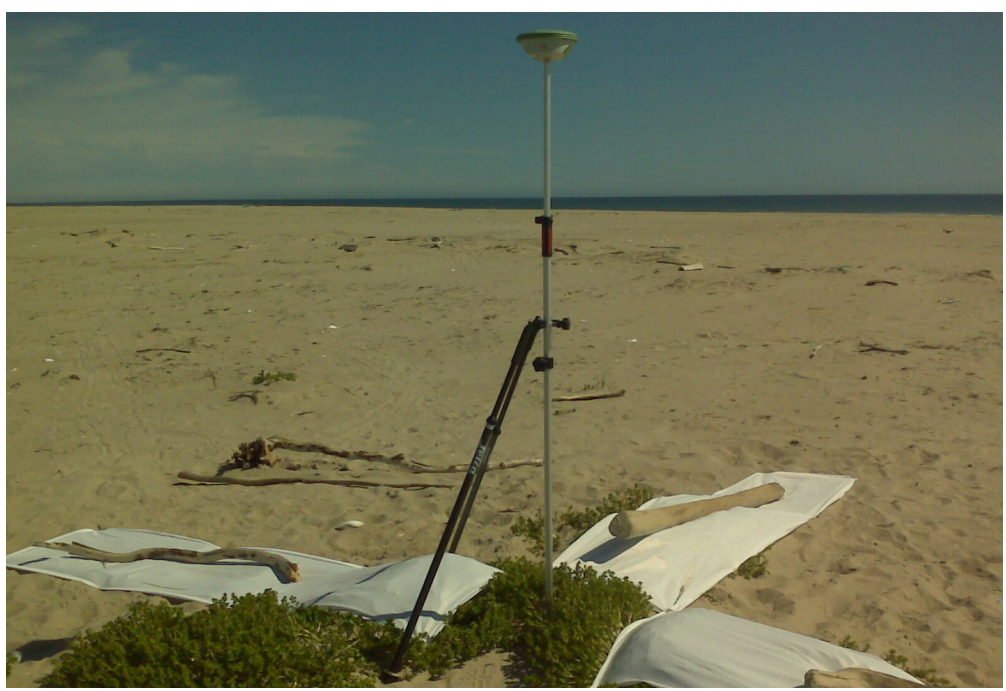

Fig 10 Static GPS Positioning of an Aerial Target on Sable Island. 

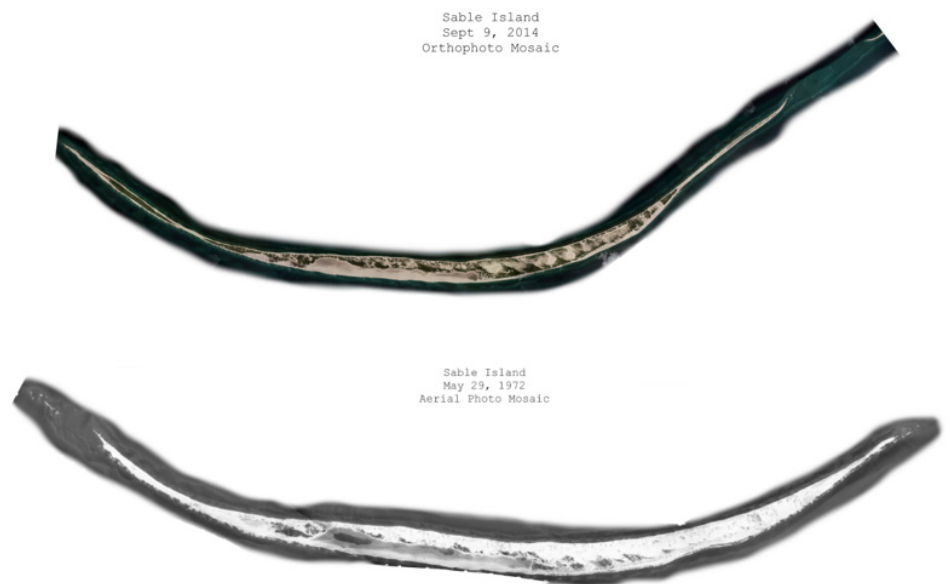

Fig 11 Sable Island in September of 2014 (top) and May of 1972 (bottom)

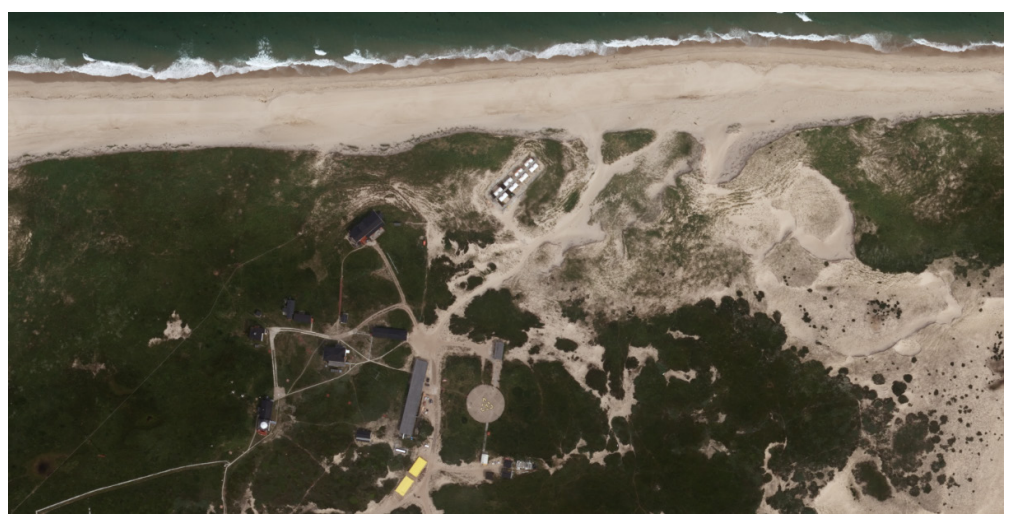

Fig 12 View of Main Station from 2014 imagery.

The SABL ACS was also used to calculate position of an aircraft capturing LiDAR data for the Centre of Geographic Sciences'(COGS) Applied Geomatics Research Group (AGRG). While on Sable Island, AGRG members were able to locate and observe a survey monument on the largest sand dune on Sable Island ("Bald Dune"). That survey monument can now be re-observed using static GPS to determine how the dune may be moving over time. This approach can be applied to monitor changes in position for any features of interest on the island.

Since SABLACS was installed in June 2014, data has been archived on a daily basis. The data was recently processed using Natural 
Resources Canada's Precise Point Positioning (PPP) GPS processing service to analyze long term position trends. The UTM easting, UTM northing and ellipsoidal height components of the position solutions are plotted in Fig 13. Daily solutions were smoothed using a 2 week moving average. The following observations are made:

i) The solution components show up to $10 \mathrm{~mm}$ variability in position (in the smoothed solutions) over the course of the year. This is likely caused by seasonal temperature effects of the structure.

ii) The north component is approximately $5 \mathrm{~mm}$ larger than it was last year. The east and height components are within a few $\mathrm{mm}$ of their starting positions. At least another year of data is required to better isolate thermal effects from tectonic plate movement.

iii) The position of the antenna installed on the garage at Main Station appears to be moving at a similar rate (same magnitude) as the mainland of Nova Scotia. The velocity field for the mainland illustrates movements of 1-2 millimeters per year horizontally and 2-3 millimeters per year vertically (Craymer et al., 2012). As more data is collected, a more accurate velocity estimate will be determined for the Island.

\section{CONCLUSION}

Since 1968, the Province of Nova Scotia has provided coordinate referencing infrastructure to allow accurate positions to be determined. This infrastructure was extended to Sable Islands in the early 1980s. Prior to that, various federal initiatives were conducted to meet positioning needs on the Island. The rich history of coordinate referencing activities on Sable Island has been summarized to link future surveys to historic work.

Each advance in positioning technology over the past century has improved abilities to locate features on Sable Island. Most recently, a permanent, active, GPS station was installed on Sable Island through a collaborative effort between the Province of Nova Scotia and Parks Canada. It was expected that the technology would offer several benefits to those involved with the Island's operations. Shortly after installation, several of those benefits were realized including: allowing for aircraft positions to be accurately calculated, enabling precise survey work and allowing changes in the position of Sable Island to 


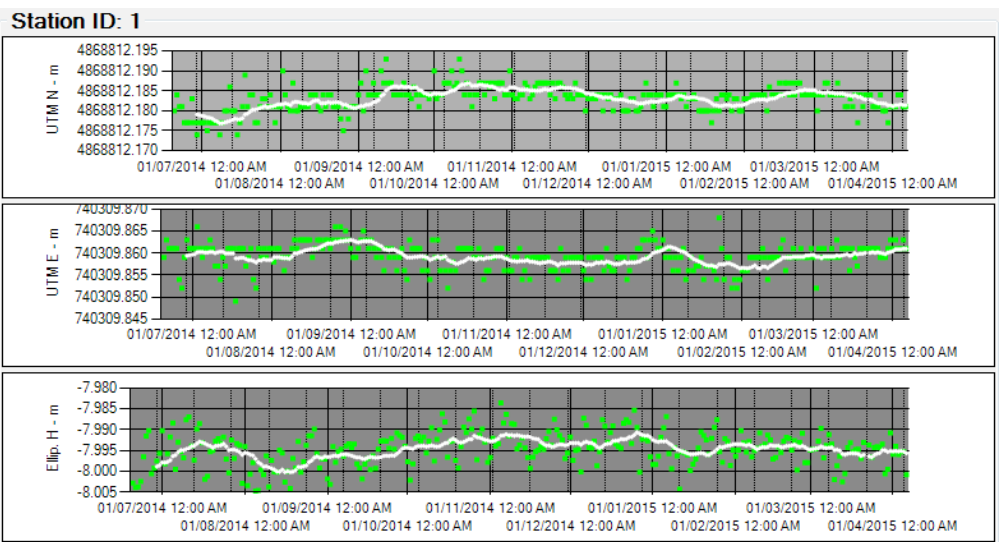

Fig 13 Position of SABL ACS from June, 2014 to April, 2015 (Green = Daily solutions, White $=2$ week smoothed solutions).

be accurately monitored. It will require at least another year of data to begin to isolate seasonal influences from actual position displacement of the ACS. Based on results at this time, the rate of movement of the landmass around Main Station appears to be within the same order of magnitude as the main land of Nova Scotia. By observing other features of interest (e.g., Bald Dune), their rates of movement can be determined as well.

Acknowledgements This work could not have been completed without the input and assistance of Michael Craymer, Earl Lapelle and Bob Morris (retired) - Canadian Geodetic Survey, John Ells - Canadian Hydrographic Service, Bill Robertson - retired Manager of LRIS Control Surveys Section, Bert Seely - former manager of the Nova Scotia Geomatics Centre, Ray Pottier - formerly with McElhanney, Brian Pyke - formerly with Nortech, Sherod Crowell - formerly with McElhanney and Nortech. Special thanks to Parks Canada for their collaboration in installing SABL ACS.

\section{REFERENCES}

Aerospace. (2010). Transit: The GPS Forefather. Aerospace.org http:// www.aerospace.org/2013/12/31/transit-the-gps-forefather/ . Accessed on 16 June 2015.

CHS. (1963). Field Operations on Sable Island. Internal Survey Report received through request for information. 
Craymer, M.R., Ferland, R., Henton, J., Lapelle, E., Mander, A. \& Piraszewski, M. (2012). National and International Reference Frames. Presentation by Geodetic Survey Division, Natural Resources Canada to the Canadian Geodetic Reference Systems Committee, May 28-30, 2012, Ottawa, Canada.

Crowell, S. (2015). Former Nortech Electronics Technician. Personal communication.

Gray, D.H. (1971). Quality of Work in Sable Island - 1963 CHS Survey. Report, Nautical Geodesy Section, Canadian Hydrographic Service, Department of Fisheries and Oceans.

Henton, J.A, Craymer, M.R., Ferland, R., Dragert, H., Mazzotti, S., \& Forbes, D.L. (2006). Crustal Motion and Deformation Monitoring of the Canadian Landmass. Geomatica, Vol. 60, No. 2.

Lapelle,E. (2015). Earl Lapelle, Geodetic Technologist, Canadian Geodetic Survey, Natural Resources Canada. Personal communication.

Morris, R.J.(2015). Senior Geodetic Surveyor (retired), Canadian Geodetic Survey, Natural Resources Canada. Personal communication.

NSLUC. (1995). A Coordinate Referencing Policy for the Province of Nova Scotia. Nova Scotia Land Use Committee.

Pottier,R. (2015). Former McElhanney surveyor. Personal communication. Pyke,B.(2015). Former Nortech Project Manager. Personal communication.

Roberston, W. (2015). Manager of Land Registration and Information Services Control Surveys Division (retired). Personal communication.

Stephens, D.E. (1973). Lighthouses of Nova Scotia. Lancelot Press, Windsor, Nova Scotia, Canada.

Swan,M.T.(1985). Memorandum: Horizontal Readjustment of Sable Island. Adopted NAD27 Positions. M83-205. Internal Memorandum received through request for information.

Tuttle, A.C. (1967). Aerodist in Geodetic Surveying in Canada. The Canadian Surveyor, June 1967.

USGS. (2013). Historical Mapping Photographs. United States Geological Survey. http://online.wr.usgs.gov/outreach/historicPhotos/enlarged/ archive_FG067.html. Accessed on 16 June 2015.

Wells, D.E. (1974). Doppler Satellite Control. Technical Report \#29, Department of Geodesy and Geomatics Engineering, University of New Brunswick, Canada. http://www2.unb.ca/gge/Pubs/TR29.pdf.

Whitney, D. (1975). The Lighthouse. McClelland and Stewart Limited, Toronto. 